\title{
The total cost of logistics in supplier selection, under conditions of multiple sourcing, multiple criteria and capacity constraint
}

\author{
Elnaz Bani and Davood Jafari*
}

Department of Industrial Engineering,Parand Branch, Islamic Azad University, Parand, Iran

\begin{tabular}{l}
\hline C H R O N I C L E \\
\hline Article history: \\
Received June 25, 2015 \\
Received in revised format: \\
October 12, 2015 \\
Accepted December 15, 2015 \\
Available online \\
December 172015 \\
\hline Keywords: \\
Supplier selection \\
Invasive weed optimization \\
Multi-objective decision making \\
\hline
\end{tabular}

\section{A B S T R A C T}

\begin{abstract}
This paper presents a mathematical model to solve a multi-objective decision making supplier selection problem. The proposed problem considers three objective functions: the first objective function minimizes the cost of purchasing the products while the second objective function minimizes the due dates and finally the third objective function maximizes the customer satisfaction. The resulted problem is formulated as mixed integer programming and, therefore, we use invasive weed optimization technique to solve the resulted problem. The performance of the proposed model is compared with NSGA II based on different criteria such as mean ideal distance and quality matrix. The preliminary results indicate that the proposed model performs relatively well compared with alternative method.
\end{abstract}

(c) 2016 Growing Science Ltd. All rights reserved.

\section{Introduction}

Supply chain management (SCM) plays an important role for management of integrated production systems (Weber et al., 1991). Oliver and Webber (1982) are believed to be the first who introduced the idea of SCM. In a simple SCM, raw materials are supplied to manufacturers from different firms and the final products are delivered from manufacturer to customers through different distribution channels. Selection of an appropriate supplier for purchasing raw materials play a key role on the success of cost minimization. There are literally various studies associated with design and optimization in SCM problems. Ghodsypour and O'brien $(1998,2001)$ proposed a simple method for cost minimization in supplier selection, under conditions of multiple sourcing, multiple criteria and capacity constraint. They used analytical hierarchy process (AHP) (Saaty, 1988) to rank different supplies in terms of quality, cost, reliability, etc. and then using a linear programming problem, they proposed a mathematical model to determine the amount of orders, which has to be purchased from each supplier. $\mathrm{Ng}$ (2008) presented an efficient and simple technique for multiple criteria supplier selection problem. Ozkok and Tiryaki

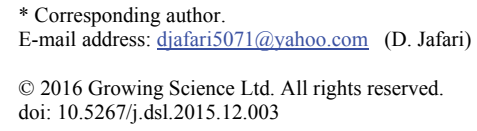


(2011) presented a compensatory fuzzy technique to multi-objective linear supplier selection problem with multiple-item.

Golmohammadi et al. (2009) developed a decision-making model to select suppliers based on multilayer feed forward neural networks. They defined a set of input functions for supplier selection criteria to generate input data for training their proposed model. Both kinds of criteria, qualitative and quantitative, were taken into account and fuzzy techniques were implemented to convert qualitative data to quantitative data. They used the neural network model structure and examined based on backpropagation. Their results of the neural network model showed that the proper structure of the model maintained a crucial impact on its performance. In addition, the selection of suitable initial weights, learning rate and momentum were considered critical in contributing the model performance.

Narasimhan et al. (2006) proposed a model to contribute to the sourcing literature by an approach for optimally choosing suppliers and supplier bids given the importance of multiple criteria across multiple products over their product life cycles. Senvar et al. (2014) presented multi criteria supplier selection based on a fuzzy PROMETHEE approach with an application to supplier selection decision problem. The primary objective of the method was the user friendliness coming from the linguistic evaluations, and the consideration of the vagueness or fuzziness inherent to the decision making environment. Shahroudi and Rouydel (2012) applied a multi-criteria decision making approach to evaluate suppliers in Iran's auto industry.

Talluri and Narasimhan (2003) proposed a max-min productivity based approach, which derives vendor performance variability measures. The proposed method then was utilized in a non-parametric statistical technique in determining vendor groups for supplier selection. The benefit of this method is that it gives the buyer with effective alternative choices within a vendor group. Ting and Cho (2008) provided tradeoffs among various objectives, which are more consistent with the complexity and nature of the real-world decision-making environment.

\section{The proposed study}

This paper presents a mathematical model to solve a multi-objective decision making supplier selection problem.

\subsection{Assumptions}

1. The buyer is able to purchase products from several suppliers.

2. This model is multi-product and each supplier can provide several products for the buyer.

3. The total amount for each product, as well as the number of suppliers is known in advance.

4. Buyer only purchases for one single period.

5. There is fixed budget to purchase all products.

6. Acceptable Quality Limit(AQL) is an acceptable desirable level determined between buyer and supplier.

7. The model considers a score for the number of years each supplier holds ISO9001 certeficate $\left(T_{i}\right)$ (Vander Wiele et al., 2001) and ISO10004( $\left.\mathrm{T}_{\mathrm{i}}^{\prime}\right)$ and they are given in Table 1 as follows,

\section{Table 1}

The scores assigned for the number of years of holding ISO certificates

\begin{tabular}{lccccc}
\hline Year & 1 & 2 & 3 & 4 & $\geq 5$ \\
\hline $\mathrm{T}_{\mathrm{i}}$ & 0.2 & 0.4 & 0.6 & 0.8 & 1 \\
$\mathrm{~T}_{\mathrm{i}}^{\prime}$ & 0.2 & 0.4 & 0.6 & 0.8 & 1 \\
\hline
\end{tabular}




\subsection{Indices}

In this paper, $i$ and $j$ are associated with suppliers and products, respectively.

\subsection{Parameters}

$d_{i j} \quad$ The mean of defective items for product $i$ purchased from supplier $j$

$P_{i j} \quad$ Price of product $i$ purchased from supplier $j$

$t_{i j} \quad$ Delay of delivery of product $i$ purchased from supplier $j$

$B_{T} \quad$ Total available budget for purchasing different products

$D_{j} \quad$ Demand for product $j$

$S_{i j} \quad$ Minimum capacity for product $i$ purchased from supplier $j$

$\mathrm{S}_{\mathrm{ij}}^{\prime} \quad$ Maximum capacity for product $i$ purchased from supplier $j$

$R_{i j} \quad$ Minimum order for product $i$ purchased from supplier $j$

$\mathrm{R}_{\mathrm{ij}}^{\prime} \quad$ Maximum order for product $i$ purchased from supplier $j$

$\mathrm{T}_{\mathrm{i}} \quad$ The number of years a supplier holds ISO9001

$\mathrm{T}_{\mathrm{i}}^{\prime} \quad$ The number of years a supplier holds ISO10004

$\mathrm{M} \quad$ Maximum number of suppliers

$\mathrm{AQL}_{j} \quad$ Maximum percetnatage level of mismatched parts purchased from a supplier $j$

\subsection{Decision variables}

$x_{i j} \quad$ The amount of product $i$ purchased from supplier $j$

$y_{i j} \quad$ Binnary variable, which is one if part $i$ is purchased from supplier $j$ and zero, otherwise

\subsection{Objective functions}

The proposed study considers the following three objective functions,

$$
\begin{aligned}
\min Z_{1} & =\sum_{i=1}^{m} \sum_{j=1}^{n} P_{i j} x_{i j} \\
\min Z_{2} & =\sum_{i=1}^{m} \sum_{j=1}^{n} t_{i j} x_{i j} \\
\min Z_{3} & =\sum_{i=1}^{m} \sum_{j=1}^{n}\left(1-d_{i j}\right) x_{i j}+\sum_{i=1}^{m} \sum_{j=1}^{n}\left(T_{i}+T_{i}^{\prime}\right) y_{i j}
\end{aligned}
$$

subject to

$$
\begin{aligned}
& \sum_{\mathrm{i}=1}^{m} \sum_{\mathrm{j}=1}^{\mathrm{n}} \mathrm{P}_{\mathrm{ij}} \mathrm{x}_{\mathrm{ij}} \leq \mathrm{B}_{\mathrm{T}} \\
& \sum_{\mathrm{i}=1}^{\mathrm{m}} \mathrm{x}_{\mathrm{ij}}\left(1-\mathrm{d}_{\mathrm{ij}}\right) \geq \mathrm{D}_{\mathrm{j}} j=1, \ldots, n \\
& \mathrm{~S}_{\mathrm{ij}} \mathrm{y}_{\mathrm{ij}} \leq \mathrm{x}_{\mathrm{ij}} \leq \mathrm{S}_{\mathrm{ij}}^{\prime} \mathrm{y}_{\mathrm{ij}} \\
& \mathrm{R}_{\mathrm{ij}} \mathrm{y}_{\mathrm{ij}} \leq \mathrm{x}_{\mathrm{ij}} \leq \mathrm{R}_{\mathrm{ij}}^{\prime} \mathrm{y}_{\mathrm{ij}} \\
& \sum_{\mathrm{i}=1}^{\mathrm{m}} \sum_{\mathrm{j}=1}^{\mathrm{n}} \mathrm{y}_{\mathrm{ij}} \leq \mathrm{M} \\
& \mathrm{y}_{\mathrm{ij}}=\left\{\begin{array}{l}
1 \quad \text { if product } \mathrm{j} \text { is purchased from supplier } \mathrm{i} \\
0
\end{array}\right. \\
& \sum_{\mathrm{i}=1}^{\mathrm{m}} \frac{\mathrm{x}_{\mathrm{ij}} \mathrm{d}_{\mathrm{ij}} \leq \mathrm{AQL}}{\mathrm{D}_{\mathrm{j}}, \mathrm{j}=0, \cdots, \mathrm{n}} \\
& \mathrm{x}_{\mathrm{ij}} \geq 0, \mathrm{i}=1, \cdots, \mathrm{m} \mathrm{j}=1, \cdots, \mathrm{n}
\end{aligned}
$$


As we can observe from the mode, the proposed problem considers three objective functions: the first objective function given in Eq. (1) minimizes the cost of purchasing the products while the second objective function, Eq. (2), minimizes the due dates and finally the third objective function, Eq. (3) maximizes the customer satisfaction. The third objective function consists of two parts as follows,

$$
\max Z_{3}=\frac{\sum_{i=1}^{m} \sum_{j=1}^{n}\left(1-d_{i j}\right) x_{i j}}{\sum_{i=1}^{m} \sum_{j=1}^{n} \frac{D_{j}}{1-d_{i j}}}+\sum_{i=1}^{m} \sum_{j=1}^{n} \frac{T_{i}+T_{i}^{\prime}}{2} y_{i j} .
$$

Here $\sum_{\mathrm{i}=1}^{m} \sum_{\mathrm{j}=1}^{\mathrm{n}} \frac{\mathrm{D}_{\mathrm{j}}}{1-\mathrm{d}_{\mathrm{ij}}}$ represents total amount of demand, which must be met. Eq. (4) determines total amount of required budget, Eq. (5) determines the demand for each product, Eq. (6) and Eq. (7) determine that when a part $i$ is ordered from supplier $j$, the number of orders must be within the capacity and required demand, respectively. Eq. (8) determines the number of suppliers, Eq. (9) shows the nature of variable $y$ and finally, Eq. (10) represents the allowable defects for each part. The proposed study of this paper has been formulated as mixed integer programming and we need to use metaheuristics to solve the resulted mode.

\section{The solution procedure}

The proposed study of this paper uses two metaheuristics, non-dominated solution genetic algorithm (NSGA II) and invasive weed optimization (IWO) techniques to solve the resulted problem.

\subsection{NSGA II}

Deb et al. (2000) appears to be the first who introduced NSGA II for multi-objective optimization. Since we deal with more than one optimal solution we need to handle multiple objective functions. Therefore, the study shows all efficient solutions in a set of Pareto optimal solutions. The following presents the implementation of NSGAII originally developed by Parhizkari et al. (2013).

Step 1: Chromosome setting: The structure of the chromosome is assigned based on a matrix.

Step 2: Evaluation: All generated solutions are evaluated based on objective functions.

Step 3: Split solutions into dominated and non-dominated groups,

Step 4: Calculate design parameter: In this step, for each member of each group, determine a parameter to compute the distance from the other members of group.

Step 5: Prepare a strategy to select parents for the next generation,

Step 6: Execute two mutation and crossover operations to build the new generation of solutions.

Step 7: Termination criteria: The proposed study of this paper ends after some stopping criteria are met.

\subsection{Invasive Weed Optimization (IWO)}

Invasive Weed Optimization (IWO) (Mehrabian \& Lucas, 2006; Nikokalam-Mozafar et al., 2014) is a meta-heuristic algorithm that mimics the colonizing nature of weeds and the algorithm can be summarized as follows:

- Initialization: A finite number of weeds are generated at the same element position of the traditional array, which maintains a uniform spacing of $(\lambda / 2)$ between neighboring elements. 
- Reproduction: Each member of the population is permitted to generate seeds according to its own and the colony's lowest and highest fitness, so that, the number of seeds generated by a weed increases linearly from the lowest possible seed for a weed with the worst fitness to the maximum number of seeds for a particular plant with the best fitness.

- Spatial distribution: The produced seeds are being distributed over the n-dimensional search space randomly through normally distributed random numbers with mean equal to zero; but different variances. This step helps us understand that the produced seeds would be built around the parent weed, leading to a local search around each plant but, the standard deviation (SD) of the random function is considered to decrease over the iterations.

In this paper, seed is generated as follows,

$\operatorname{seed}_{i}=$ floor $\left(s_{\min }+\left(s_{\max }-s_{\min }\right) \times\left(\left(\right.\right.\right.$ popsize $_{\text {iter }}-$ rank $\left._{i}\right) /\left(\right.$ popsize $\left._{\text {iter }}-1\right)$

where $S_{\min }, S_{\max }$, popsizeiter represent minimum seed, maximum seed and population size, respectively.

- Competitive Exclusion: If a particular plant quits no offspring then it should go extinct, otherwise they could take over the world. Thus, we have to find some kind of competition between plants for limiting maximum number of plants in a colony. In the beginning, the plants in a colony reproduces quickly and all the produced plants are included in the colony, until the number of plants in the colony achieve a maximum value, pop $_{\max }$. We need to keep in mind that by this time the fitter plants have reproduced more than undesirable plants. Therefore, only the fittest plants, among the existing ones and the reproduced ones; are considered in the colony and the above steps are repeated until the maximum number of iterations are met (Basak et al., 2010).

\section{The results}

The first step for the implementation of the NSGA II and IWO, the study has used response surface modeling and Table 2 and Table 3 demonstrate the parameters.

Table 2

The input parameters for the implementation of NSGA II

\begin{tabular}{cccc}
\hline Factors & Symbol & Optimal Coded & Optimal Value \\
\hline n-pop & $\mathrm{X} 1$ & 0 & 100 \\
pc & $\mathrm{X} 2$ & 0 & 0.8 \\
pmu & $\mathrm{X} 3$ & -0.45 & 0.1 \\
Type-Crossover & $\mathrm{X} 4$ & -1 & 1Point \\
\hline
\end{tabular}

Table 3

The input parameters for IWO

\begin{tabular}{cccc}
\hline Factors & Symbol & Optimal Coded & Optimal Value \\
\hline n-pop & X1 & 0 & 100 \\
Pm & X2 & -0.58 & 0.1 \\
Pow & X3 & 0.4 & 4 \\
Sigmainitial & X4 & 0 & 0.5 nProduct \\
Smax & X5 & 1 & 3 \\
Smin & X6 & -0.45 & 1 \\
\hline
\end{tabular}


Since we plan to compare the performance of two methods, the initial population for two methods is set to 100 . When there is more than one objective function, we need to use Quality metric (QM), Mean ideal distance (MID), Spacing metric (SM) and Diversification metric (DM) to compare Pareto optimal solutions. To compute QM, the contribution of NSGA II and IWO from Pareto solutions is demonstrated by this factor by putting together the nondominated solutions detected by the algorithms and measuring the ratios between non-dominated solutions of each algorithm, where a method with a higher value of the QM shows better performance. In this paper, MID and DM are calculated as follows,

$$
\begin{aligned}
& \text { MID }=\frac{\sum_{i=1}^{n} \sqrt{\left(\frac{\mathrm{f}_{1 \mathrm{i}}-\mathrm{f}_{1}^{\text {best }}}{\mathrm{f}_{1, \text { total }}^{\text {max }}-\mathrm{f}_{1, \text { total }}^{\text {min }}}\right)^{2}+\left(\frac{\mathrm{f}_{2 \mathrm{i}}-\mathrm{f}_{2}^{\text {best }}}{\mathrm{f}_{2, \text { total }}^{\text {max }}-\mathrm{f}_{2, \text { total }}^{\text {min }}}\right)^{2}+\left(\frac{\mathrm{f}_{3 i}-\mathrm{f}_{3}^{\text {best }}}{\mathrm{f}_{3, \text { total }}^{\text {max }}-\mathrm{f}_{3, \text { total }}^{\text {min }}}\right)^{2}}}{\mathrm{n}} \\
& \mathrm{DM}=\sqrt{\left(\frac{\max \mathrm{f} 1 \mathrm{i}-\operatorname{minf} 1 \mathrm{i}}{\mathrm{f}_{1, \text { total }}^{\max }-\mathrm{f}_{1, \text { total }}^{\min }}\right)^{2}+\left(\frac{\max 2 \mathrm{i}-\operatorname{minf} 2 \mathrm{i}}{\mathrm{f}_{2, \text { total }}^{\max }-\mathrm{f}_{2, \text { total }}^{\min }}\right)^{2}+\left(\frac{\max \mathrm{f} 3 \mathrm{i}-\operatorname{minf} 3 \mathrm{i}}{\mathrm{f}_{3, \text { total }}^{\max }-\mathrm{f}_{3, \text { total }}^{\min }}\right)^{2}}
\end{aligned}
$$

Here $\mathrm{f}_{1}^{\text {best }}, \mathrm{f}_{2}^{\text {best }}$ and $\mathrm{f}_{3}^{\text {best }}$ are associated with the best solution found for the objective functions of $\mathrm{Z}_{1}$, $Z_{2}$ and $Z_{3}$, respectively. In addition, in the index min and max represent the minimum and the maximum objective functions found, respectively. Moreover, SM is calculated as follows,

$$
S M=\frac{\sum_{i=1}^{n}\left|\bar{d}-d_{i}\right|}{(n-1) \bar{d}}
$$

where $d_{i}$ is the Euclidean distance between consecutive solutions in the calculated nondominated set of solutions and $\bar{d}$ is the average of these distances. For more details see Sedehzadeh et al. (2014). Table 4 presents the results of the implementation of two methods. Moreover, Fig. 1 shows the performance of two methods in terms of four criteria.

\begin{tabular}{|c|c|c|c|c|c|c|c|c|c|}
\hline \multirow{2}{*}{$\begin{array}{l}\vec{E} \\
\frac{E}{\sigma} \\
\frac{\sigma}{\sigma} \\
\vec{\omega}\end{array}$} & \multirow[b]{2}{*}{ 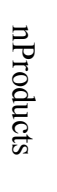 } & \multicolumn{2}{|c|}{ (QM) } & \multicolumn{2}{|c|}{ (MID) } & \multicolumn{2}{|c|}{$(\mathrm{DM})$} & \multicolumn{2}{|c|}{$(\mathrm{SM})$} \\
\hline & & $\begin{array}{l}Z \\
Z \\
\Omega \\
\Omega \\
D \\
=\end{array}$ & $\begin{array}{l}3 \\
0 \\
3\end{array}$ & 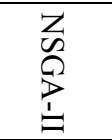 & $\begin{array}{l}3 \\
\stackrel{3}{0} \\
ٍ\end{array}$ & $\begin{array}{l}Z \\
Z \\
\Omega \\
\Omega \\
\stackrel{1}{1} \\
=\end{array}$ & $\begin{array}{l}3 \\
\stackrel{0}{3} \\
ٍ\end{array}$ & 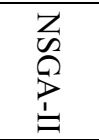 & $\begin{array}{l}3 \\
0 \\
\vdots \\
0\end{array}$ \\
\hline 10 & 5 & 0.357 & 0.643 & 0.735 & 0.684 & 1.423 & 1.423 & 1.321 & 1.267 \\
\hline 10 & 10 & 0.25 & 0.75 & 0.781 & 0.675 & 1.423 & 1.423 & 1.231 & 1.228 \\
\hline 20 & 5 & 0.335 & 0.665 & 0.764 & 0.686 & 1.423 & 1.423 & 1.132 & 1.228 \\
\hline 20 & 10 & 0.257 & 0.743 & 0.746 & 0.697 & 1.423 & 1.423 & 1.132 & 1.269 \\
\hline 20 & 20 & 0.248 & 0.752 & 1.075 & 0.884 & 1.72 & 1.82 & 1.22 & 1.154 \\
\hline 30 & 10 & 0.131 & 0.869 & 1.398 & 0.664 & 0.76 & 1.37 & 1.501 & 1.423 \\
\hline 30 & 20 & 0.118 & 0.882 & 0.815 & 0.708 & 1.272 & 1.45 & 1.487 & 1.411 \\
\hline 40 & 40 & 0.157 & 0.843 & 0.749 & 0.674 & 1.238 & 1.3 & 1.45 & 1.427 \\
\hline 50 & 20 & 0 & 1 & 2.017 & 0.657 & 0.47 & 1.412 & 1.374 & 1.352 \\
\hline 50 & 30 & 0 & 1 & 1.597 & 0.625 & 0.602 & 1.224 & 1.374 & 1.354 \\
\hline 80 & 70 & 0 & 1 & 2.202 & 0.619 & 0.395 & 1.365 & 1.285 & 1.142 \\
\hline 100 & 40 & 0 & 1 & 3.599 & 0.627 & 0.838 & 1.414 & 1.751 & 1.391 \\
\hline 100 & 50 & 0 & 1 & 9.54 & 0.719 & 0.588 & 1.154 & 1.751 & 1.071 \\
\hline 100 & 60 & 0 & 1 & 11.004 & 0.713 & 1.025 & 1.412 & 1.4 & 1.397 \\
\hline 100 & 70 & 0 & 1 & 19.345 & 0.858 & 0.201 & 1.412 & 1.665 & 1.212 \\
\hline
\end{tabular}

\section{Table 4}

The symmary of the performance of NSGA II versus multi objective IWO (MOIWO) 


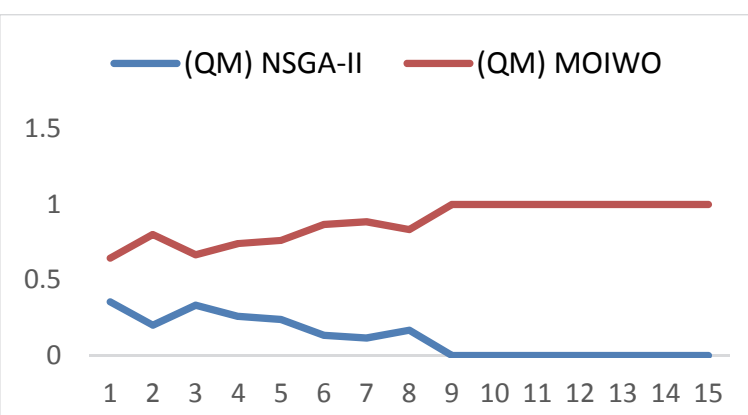

The performance of two method in terms of Quality metric (QM)

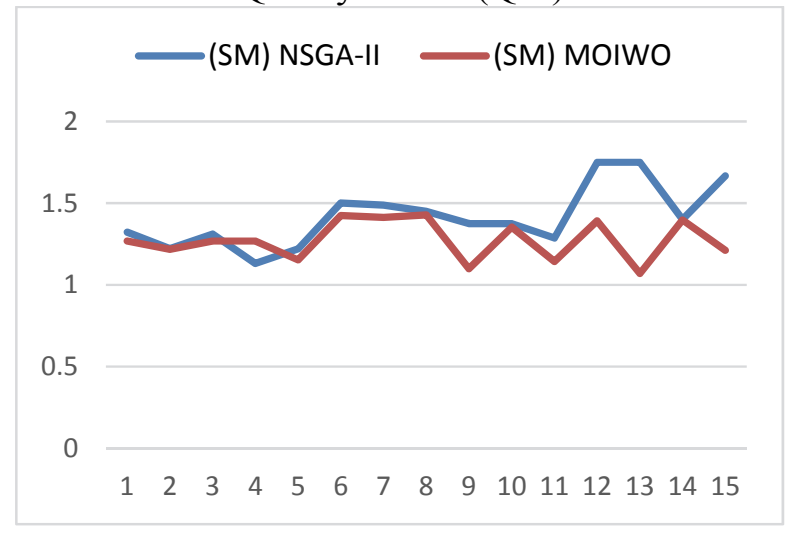

The performance of two method in terms of Spacing metric (SM)

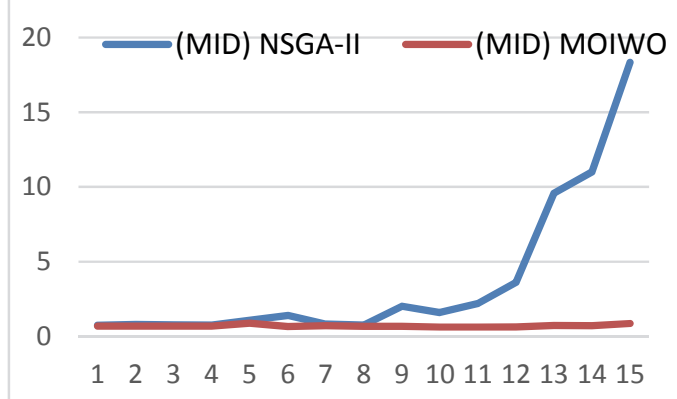

The performance of two method in terms of Mean ideal distance (MID)

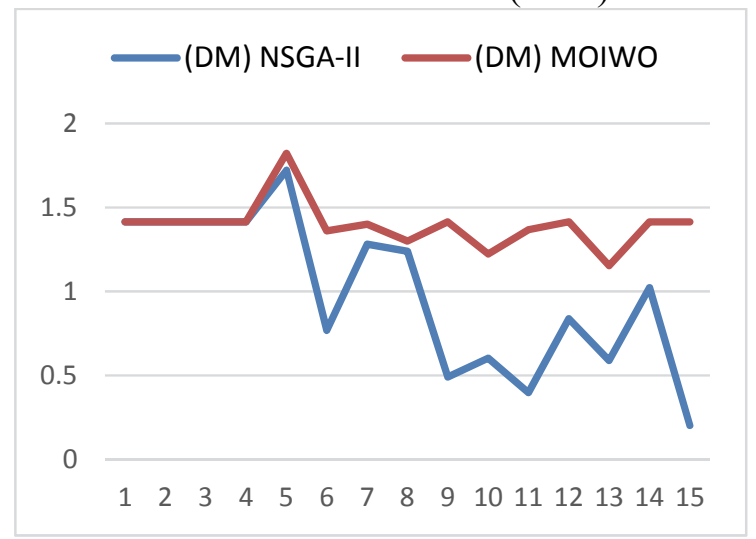

The performance of two method in terms of Diversification metric (DM)

Fig. 1. The performance of NSGA II versus MOIWO

\section{Discussion and conclusion}

In this paper, we have presented a mathematical model to solve a multi-objective decision making supplier selection problem. The proposed problem has considered three objective functions: the first objective function minimizes the cost of purchasing the products while the second objective function minimizes the due dates and finally the third objective function maximizes the customer satisfaction. The resulted problem has been formulated as mixed integer programming and, therefore, we have used IWO technique to solve the resulted problem. The performance of the proposed model has been compared with NSGA II based on different criteria such as mean ideal distance and quality matrix. The preliminary results have indicate that the proposed model performs relatively well compared with alternative method in terms of quality metric, Spacing metric, diversification metric and mean ideal distance.

\section{Acknowledgement}

The authors would like to thank the anonymous referees for constructive comments on earlier version of this paper.

\section{References}

Basak, A., Pal, S., Das, S., Abraham, A., \& Snasel, V. (2010, July). A modified invasive weed optimization algorithm for time-modulated linear antenna array synthesis. In Evolutionary Computation (CEC), 2010 IEEE Congress on (pp. 1-8). IEEE.

Deb, K., Agrawal, S., Pratap, A., Meyarivan, T. (2000). A fast elitist non-dominated sorting genetic algorithm for multi-objective optimization: NSGA-II. In: proceedings of the parallel problem solving from nature VI (PPSN-VI) conference, 849-858. 
Ghodsypour, S. H., \& O'Brien, C. (1998). A decision support system for supplier selection using an integrated analytic hierarchy process and linear programming. International journal of production economics, 56, 199-212.

Ghodsypour, S. H., \& O'brien, C. (2001). The total cost of logistics in supplier selection, under conditions of multiple sourcing, multiple criteria and capacity constraint. International Journal of Production Economics, 73(1), 15-27.

Golmohammadi, D., Creese, R. C., \& Valian, H. (2009). Neural network application for supplier selection. International Journal of Product Development, 8(3), 252-275.

Mehrabian, A. R., \& Lucas, C. (2006). A novel numerical optimization algorithm inspired from weed colonization. Ecological informatics, 1(4), 355-366.

Narasimhan, R., Talluri, S., \& Mahapatra, S. K. (2006). Multiproduct, multicriteria model for supplier selection with product life-cycle considerations. Decision Sciences, 37(4), 577-603.

Nikokalam-Mozafar, S. H., Ashjari, B., Tavakkoli-Moghaddam, R., \& Omidvar, A. (2014). Solving a multi-objective chance-constrained hub covering location problem by discrete invasive weed optimization. Cogent Engineering, 1(1), 991526.

Oliver, R. K., \& Webber, M. D. (1982). Supply-chain management: logistics catches up with strategy. Outlook, 5(1), 42-47.

Ozkok, B. A., \& Tiryaki, F. (2011). A compensatory fuzzy approach to multi-objective linear supplier selection problem with multiple-item. Expert Systems with Applications, 38(9), 11363-11368.

$\mathrm{Ng}$, W. L. (2008). An efficient and simple model for multiple criteria supplier selection problem. European Journal of Operational Research, 186(3), 1059-1067.

Parhizkari, M., Amiri, M., \& Mousakhani, M. (2013). A multiple criteria decision making technique for supplier selection and inventory management strategy: A case of multi-product and multisupplier problem. Decision Science Letters, 2(3), 185-190.

Saaty, T. L. (1988). What is the analytic hierarchy process? (pp. 109-121). Springer Berlin Heidelberg.

Sedehzadeh, S., Tavakkoli-Moghaddam, R., Mohammadi, M., \& Jolai, F. (2014). Solving a new priority $\mathrm{M} / \mathrm{M} / \mathrm{C}$ Queue model for a multi-mode hub covering location problem by multi-objective parallel simulated annealing. Economic Computation and Economic Cybernetics studies and Research, 48(4), 299-318.

Senvar, O., Tuzkaya, G., \& Kahraman, C. (2014). Multi criteria supplier selection using fuzzy PROMETHEE method. In Supply Chain Management Under Fuzziness (pp. 21-34). Springer Berlin Heidelberg.

Shahroudi, K., \& Rouydel, H. (2012). Using a multi-criteria decision making approach (ANP-TOPSIS) to evaluate suppliers in Iran's auto industry.International Journal of Applied Operational Research, 2(2), 37-48.

Talluri, S., \& Narasimhan, R. (2003). Vendor evaluation with performance variability: a max-min approach. European Journal of Operational Research,146(3), 543-552.

Ting, S. C., \& Cho, D. I. (2008). An integrated approach for supplier selection and purchasing decisions. Supply Chain Management: An International Journal, 13(2), 116-127.

Vander Wiele, A., Williams, A. R. T., Brown, A., \& Dale, B. G. (2001). The ISO 9000 series as a tool for organisational change: is there a case?.Business Process Management Journal, 7(4), 323-331.

Weber, C. A., Current, J. R., \& Benton, W. C. (1991). Vendor selection criteria and methods. European Journal of Operational Research, 50(1), 2-18. 